\title{
Formation of PCDD/Fs from heating polyethylene with metal chlorides in the presence of air
}

\author{
Ming-Hui Zheng, ${ }^{\mathrm{a},}$, Peng-Yan Liu ${ }^{\mathrm{a}, \mathrm{b}}$, Ming-Jun Piao ${ }^{\mathrm{a}}$, Wen-Bin Liu ${ }^{\mathrm{a}}$, Xiao-Bai Xu ${ }^{\mathrm{a}}$ \\ ${ }^{a}$ Key Laboratory of Environmental Chemistry and Ecotoxicology, Research Center for Eco-Environmental Sciences, \\ Chinese Academy of Sciences, P.O. Box 2871, Beijing 100085, PR China \\ ${ }^{\mathrm{b}}$ Department of Chemistry, Hebei University, Baoding 071002, PR China
}

Received 22 October 2002; received in revised form 18 August 2003; accepted 4 October 2003

\begin{abstract}
This paper investigated the effect of inorganic chlorine on the formation of PCDD/Fs from heating polyethylene (PE) in the presence of air. There was an increase in the formation of PCDD/Fs with an increasing amount of metal chlorides except $\mathrm{NaCl}$, which was not observed to have any effects on the formation of PCDD/Fs without the presence of catalysts. Although the levels of PCDD/Fs formation in this study have no relevance to full scale municipal solid waste incineration, the results of the present experiments can aid understanding of the mechanisms of the formation of PCDD/Fs from heating PE in the presence of metal chlorides.
\end{abstract}

(c) 2003 Elsevier B.V. All rights reserved.

Keywords: Dioxins; Polyethylene; Metal chlorides; Combustion; PCDD/Fs formation

\section{Introduction}

Formation of polychlorinated dibenzo- $p$-dioxins (PCDDs) and polychlorinated dibenzofurans (PCDFs) in combustion processes of chlorinecontaining organic materials has been frequently studied (Tuppurainen et al., 2000). Chlorine, catalysts and organic compounds are essential for these reactions. Although $\mathrm{CuCl}_{2}$ has been reported to have a significant catalytic role on $\mathrm{PCDD} / \mathrm{Fs}$ formation via the Deacon process, the function of inorganic chlorine in these reactions is not known

*Corresponding author. Tel.: + 86-10-62849172; fax: + 8610-62923563.

E-mail address: zhengmh@mail.rcees.ac.cn (M.-H. Zheng). in detail (Wikström et al., 1996; Hatanaka et al., 2003). Wilken et al. (1994) noted that excluding PVC was one of the effective measures in reducing PCDD/Fs formation. Addink and Altwicker (1999) showed that chlorine from inorganic chlorine did find its way into PCDD/Fs formed. The correlation of PCDD/Fs emission with operating parameters could help operators of municipal solid waste incinerators (MSWI) to indicate needed corrective actions (Everaert and Baeyens, 2001)

The purpose of this study was to investigate the effect of inorganic chlorine on the formation of $\mathrm{PCDD} / \mathrm{Fs}$ when polymer combustion in the absence of organic chlorine was carried out. Polyethylene (PE) was selected in this study because it is the leading plastic in total production 
in the world and also the major one in municipal solid wastes.

\section{Materials and methods}

Polyethylene (HDPE 5000S) in pellet form was the product of Yanshan Co.

Polymer combustion was conducted in a tubetype furnace. The combustion apparatus is shown in Fig. 1. The combustion chamber consisted of a quartz tube $(80 \times 4 \mathrm{~cm}$ i.d. $)$, after which came the collecting system, which included a glass wool fibre, a glass filter membrane to retain the particles, an XAD-2 adsorbents vessel and two liquid nitrogen cold traps. The air was dried by silica gel and molecular sieve adsorbents and then introduced in front of the quartz tube at $2 \mathrm{l} / \mathrm{min}$. The glass wool fibre, glass fibre membrane and the sample boat were heated at $500{ }^{\circ} \mathrm{C}$ in a muffle furnace for $2 \mathrm{~h}$ just before using, in order to remove possible organic compound contaminants.

Two gram PE was melted in a sample boat. The molten PE was mixed with different kinds of metal chlorides and cooled at room temperature. A complete experimental matrix is given in Table 1. At first, the furnace was heated to $400{ }^{\circ} \mathrm{C}$ and the dry air introduced. Then the sample boat containing $\mathrm{PE}$ was pushed into the combustion zone of the
Table 1

The variation in metal chlorides used in the experiment

\begin{tabular}{ll}
\hline Experiment No. & Inorganic chlorine \\
\hline 1 & No chlorides \\
2 & $40 \mathrm{mg} \mathrm{NaCl}$ \\
3 & $20 \mathrm{mg} \mathrm{ZnCl} 2$ \\
4 & $20 \mathrm{mg} \mathrm{CuCl}$ \\
5 & $40 \mathrm{mg} \mathrm{FeCl}{ }_{3}$ \\
6 & $40 \mathrm{mg} \mathrm{CuCl}$ \\
7 & $20 \mathrm{mg} \mathrm{NaCl}+20 \mathrm{mg} \mathrm{ZnCl}$ \\
8 & $20 \mathrm{mg} \mathrm{NaCl}_{2}+20 \mathrm{mg} \mathrm{CuCl}$ \\
9 & $20 \mathrm{mg} \mathrm{ZnCl}+20 \mathrm{mg} \mathrm{CuCl}$ \\
\hline
\end{tabular}

furnace. After the combustion, the boat was removed, the air flow stopped and the furnace switched off. The residence time of the sample in the furnace was approximately $15 \mathrm{~min}$. A blank was run between samples to check on contamination.

The glass wool fibre, glass fibre membrane, XAD-2 adsorbents, solid residues on the wall of the quartz tube and sample boat were spiked with a mixture of ${ }^{13} \mathrm{C}$-labelled PCDD/Fs (Cambridge Isotope Laboratories) prior to their $24 \mathrm{~h}$ Soxhlet extraction with toluene. The extracts were washed with concentrated sulfuric acid following concentration by rotary evaporation. The bulk of the coextracted organic material was removed by

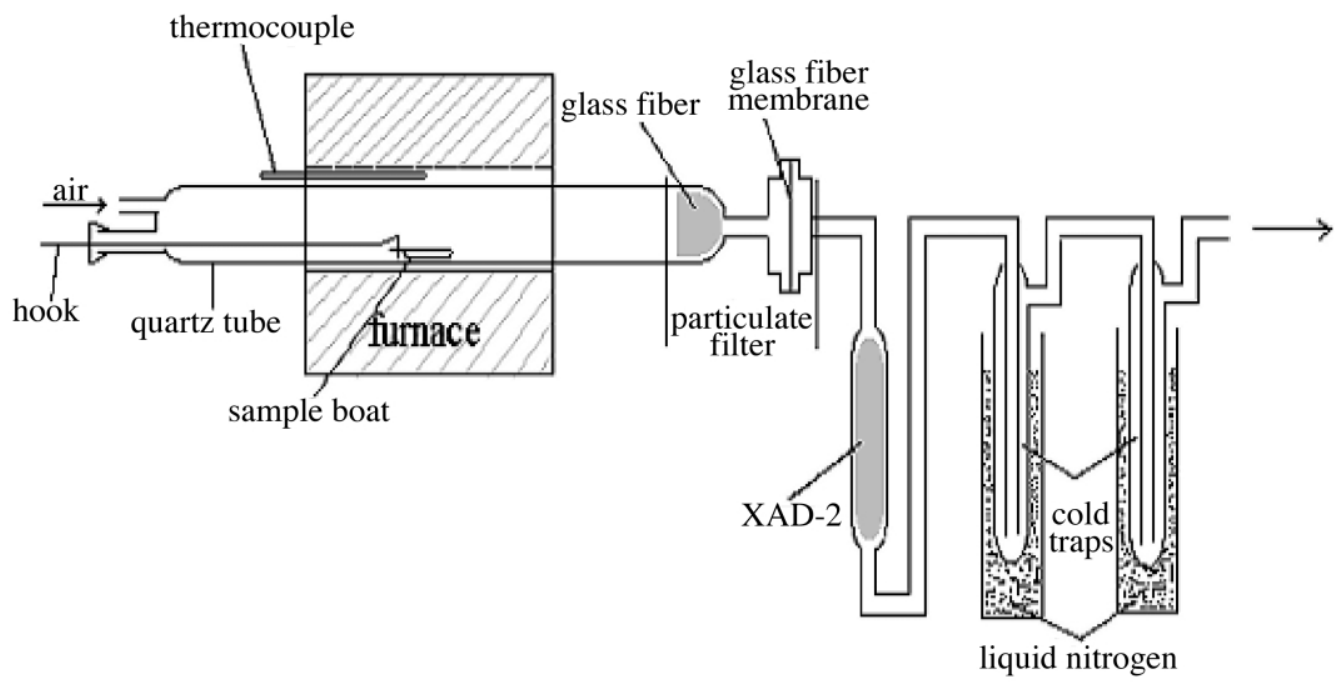

Fig. 1. Schematic of the combustion and collection system. 
successively passing the extract through the following series of chromatographic columns: silica, acid-base silica multilayer and basic alumina. Just prior to GC-MS analysis, two ${ }^{13} \mathrm{C}$-labelled recovery standards (Cambridge Isotope Laboratories) were added for the quantification of surrogate recovery. The analyses were carried out on an Agilent $6890 \mathrm{GC} / 5973 \mathrm{~N}$ MSD using a $60 \mathrm{~m} \mathrm{HP}-$ $5 \mathrm{~ms}$ fused-silica column. Quantification of PCDD/Fs was performed in selected-ion monitoring mode. For each congener the two most abundant ions of molecular ion clusters were measured.

\section{Results and discussion}

No PCDD/Fs were detected in experiment No.1, which did not contain any chlorine sources. No detectable PCDD/Fs were observed in experiment No.2, which contained only $\mathrm{NaCl}$ as a chlorine source. PCDD/Fs formation was confirmed in other experiments with transition metal chlorides. The homologue profiles of PCDD/Fs in the experiments are shown in Table 2.

It is generally accepted that the chlorine input has an influence on the formation of PCDD/Fs in thermal processes. Luijk et al. (1994) detected PCDDs in a carbon- $\mathrm{HCl}$ system with no $\mathrm{CuCl}_{2}$, in an experiment set-up basically similar to that of the present study. $\mathrm{HCl}$ seems to be an important chlorination agent for PCDD and PCDF as well as for their precursors. Compared to $\mathrm{HCl}, \mathrm{NaCl}$ has little effect on the formation of PCDD/Fs. As can be seen from Table 2, $\mathrm{NaCl}$ was an effective chlorine source in these experimental conditions, but it was not observed to have any effects on PCDD/Fs formation without catalysts. These results are in good agreement with earlier experiments by Lenoir et al. (1991), who reported no differences in the emission of PCDD/Fs between combustion experiments with or without $\mathrm{NaCl}$ in the fuel.

Table 2 shows the isomer distribution pattern of PCDDs and PCDFs. PCDFs were more dominant than PCDDs and higher chlorinated PCDD/Fs were formed preferentially for all types of experiments performed with transition metal chlorides in this study. The same trends were also observed in combustion experiments using wastes with chlo-
Table 2

The homologue profiles of PCDD/Fs in the experiments $(\mathrm{ng} / \mathrm{g}$ PE)

\begin{tabular}{|c|c|c|c|c|c|c|c|}
\hline & $3 \#$ & $4 \#$ & $5 \#$ & $6 \#$ & 7\# & $8 \#$ & $9 \#$ \\
\hline 2378-TCDF & 1.1 & 0.11 & ND & 19 & 0.86 & 2.4 & 25 \\
\hline$\Sigma \mathrm{TCDF}$ & 5.4 & 0.11 & 4.2 & 43 & 1.9 & 7.2 & 90 \\
\hline 2378-TCDD & ND & ND & ND & ND & ND & ND & ND \\
\hline$\Sigma T C D D$ & ND & ND & ND & ND & ND & ND & 7.3 \\
\hline 12378-PCDF & ND & ND & 0.72 & 1.1 & ND & 0.31 & 7.9 \\
\hline 23478-PCDF & 0.56 & ND & 0.27 & 7.9 & ND & 1.3 & 16 \\
\hline$\Sigma \mathrm{PCDF}$ & 4.4 & 0.16 & 5.2 & 84 & 3.1 & 8.8 & 166 \\
\hline 12378-PCDD & ND & ND & ND & 1.0 & ND & ND & 3.2 \\
\hline$\Sigma P C D D$ & ND & ND & ND & 18 & 5.5 & ND & 40 \\
\hline $123478-\mathrm{H}_{6} \mathrm{CDF}$ & ND & ND & 0.84 & ND & ND & 2.8 & 48 \\
\hline $123678-\mathrm{H}_{6} \mathrm{CDF}$ & ND & 0.11 & 0.47 & 8.6 & ND & 0.67 & 17 \\
\hline $123789-\mathrm{H}_{6} \mathrm{CDF}$ & 0.53 & ND & ND & 22 & ND & 1.4 & 23 \\
\hline $234678-\mathrm{H}_{6} \mathrm{CDF}$ & ND & ND & ND & ND & ND & ND & 7.5 \\
\hline$\Sigma \mathrm{H}_{6} \mathrm{CDF}$ & 3.9 & 0.20 & 3.7 & 98 & ND & 10 & 186 \\
\hline $123478-\mathrm{H}_{6} \mathrm{CDD}$ & ND & ND & ND & 1.2 & ND & ND & ND \\
\hline $123678-\mathrm{H}_{6} \mathrm{CDD}$ & ND & ND & ND & 1.6 & ND & ND & 4.3 \\
\hline $123789-\mathrm{H}_{6} \mathrm{CDD}$ & ND & ND & ND & 7.7 & ND & ND & 18.8 \\
\hline$\Sigma \mathrm{H}_{6} \mathrm{CDD}$ & ND & ND & ND & 35 & ND & ND & 46 \\
\hline $1234678-\mathrm{H}_{7} \mathrm{CDF}$ & 3.1 & 1.0 & 4.6 & 113 & 7.7 & 27 & 402 \\
\hline $1234789-\mathrm{H}_{7} \mathrm{CDF}$ & ND & ND & 0.80 & 33 & 2.9 & 3.6 & 105 \\
\hline$\Sigma \mathrm{H}_{7} \mathrm{CDF}$ & 3.9 & 1.0 & 7.6 & 215 & 11 & 41 & 647 \\
\hline $1234678-\mathrm{H}_{7} \mathrm{CDD}$ & ND & ND & ND & 24 & ND & 1.8 & 41 \\
\hline$\Sigma \mathrm{H}_{7} \mathrm{CDD}$ & 3.9 & ND & 0.77 & 44 & ND & 3.4 & 80 \\
\hline OCDD & ND & ND & ND & 38 & ND & 9.9 & 109 \\
\hline OCDF & 0.73 & 0.64 & 1.8 & 128 & 3.0 & 33 & 283 \\
\hline
\end{tabular}

$(\mathrm{ND}<0.05 \mathrm{ng} / \mathrm{g} \mathrm{PE})$.

rine sources and a $\mathrm{Cu}$ catalyst (Hatanaka et al., 2000). There was generally an increase in the formation of PCDD/Fs with an increasing amount of metal chlorides.

The experiment was designed so as to optimize PCDD/Fs formation. Although the levels of PCDD/Fs formation in this study have no relevance to full scale municipal solid waste incineration, the results of the present experiments can help an understanding of the mechanisms of the formation of PCDD/Fs from heating PE in the presence of metal chlorides.

\section{Acknowledgments}

This study was supported by National Natural Science Foundation of China. Grant No. 20177031, 20122202 and Chinese Academy of Sciences KZCX2-414. 


\section{References}

Addink R, Altwicker E. Formation experiments of polychlorinated dibenzo- $p$-dioxins/dibenzofurans with $\mathrm{Na}^{37} \mathrm{Cl}$. Organohalogen Compd 1999;41:69-72.

Everaert K, Baeyens J. Correlation of PCDD/F emissions with operating parameters of municipal solid waste incinerators. J Air Waste Manage Assoc 2001;51:718-724.

Hatanaka T, Imagawa T, Takeuchi M. Formation of PCDD/Fs in artificial solid waste incineration in a laboratory-scale fluidized-bed reactor: influence of contents and forms of chlorine sources in high-temperature combustion. Environ Sci Technol 2000;34:3920-3924.

Hatanaka T, Imagawa T, Takeuchi M. Effects of copper chloride on formation of polychlorinated dibenzo- $p$-dioxins in model waste incineration. Chemosphere 2003;51:10411046.

Lenoir D, Kaune A, Hutzinger O, Mutzenich G, Horch K. Influence of operating parameters and fuel type on PCDD/
PCDF emissions from fluidized bed incinerator. Chemosphere 1991;23:1491-1500.

Luijk R, Akkerman D, Slot P, Oile K, Kapteijn F. Mechanism of formation of polychlorinated dibenzo- $p$-dioxins and dibenzofurans in the catalyzed combustion of carbon. Environ Sci Technol 1994;26:312-321.

Tuppurainen K, Ruokojärvi P, Asikainen A, Aatamila A, Ruuskanen R. Chlorophenols as precursors of PCDD/Fs in incineration processes: correlations, PLS modeling and reaction mechanisms. Environ Sci Technol 2000;34:4958-4962.

Wikström E, Löfvenius G, Rappe C, Marklund S. Influence of level and form of chlorine on the formation of chlorinated dioxins, dibenzofurans and benzenes during combustion of an artificial fuel in a laboratory reactor. Environ Sci Technol 1996;30:1637-1644.

Wilken M, Boske J, Jager J, Zeschmar-Lahl B. PCDD/F, PCB, chlorobenzene and chlorophenol emissions of a municipal solid waste incineration plant (MSWI)-variation within a five day routine performance and influence of $\mathrm{Mg}(\mathrm{OH})_{2}$ addition. Chemosphere 1994;29:2039-2050. 